\title{
Translating novel strategies for cardioprotection: the Hatter Workshop Recommendations
}

\author{
Derek J. Hausenloy $\cdot$ Gary Baxter $\cdot$ Robert Bell $\cdot$ Hans Erik Bøtker $\cdot$ Sean M. Davidson • \\ James Downey · Gerd Heusch • Masafumi Kitakaze • Sandrine Lecour • Robert Mentzer • \\ Mihaela M. Mocanu • Michel Ovize • Rainer Schulz • Richard Shannon • Malcolm Walker • \\ Gail Walkinshaw $\cdot$ Derek M. Yellon
}

Received: 6 September 2010/Revised: 9 September 2010/ Accepted: 10 September 2010/Published online: 24 September 2010 (C) The Author(s) 2010. This article is published with open access at Springerlink.com

\begin{abstract}
Ischemic heart disease (IHD) is the leading cause of death worldwide. Novel cardioprotective strategies are therefore required to improve clinical outcomes in patients with IHD. Although a large number of novel cardioprotective strategies have been discovered in the research laboratory, their translation to the clinical setting has been largely disappointing. The reason for this failure
\end{abstract}

M. Marber, London, UK, served as guest editor for the manuscript and was responsible for all editorial decisions, including the selection of reviewers. The policy applies to all manuscripts with authors from the editor's institution.

Report of the UCL-Hatter Cardiovascular Institute 6th International Cardioprotection Workshop together with the Working Group of Cellular Biology of the Heart of the European Society of Cardiology.

\section{J. Hausenloy $\cdot$ R. Bell · S. M. Davidson}

M. M. Mocanu · M. Walker · D. M. Yellon $(\square)$

The Hatter Cardiovascular Institute, University College London

Hospitals and Medical School, 67 Chenies Mews,

London WC1E 6HX, UK

e-mail: d.yellon@ucl.ac.uk

G. Baxter

Welsh School of Pharmacy, Cardiff University,

King Edward VII Avenue, Cardiff CF10 3NB, UK

\section{H. E. Bøtker}

Department of Cardiology, Aarhus University Hospital,

Skejby Sygehus, Aarhus, Denmark

\section{J. Downey}

University of South Alabama College of Medicine, Mobile,

AL 36688, USA

\section{G. Heusch · R. Schulz}

Institute of Pathophysiology, Zentrum für Innere Medizin,

Universitätsklinikum Essen, Hufelandstraße 55,

45122 Essen, Germany can be attributed to a number of factors including the inadequacy of the animal ischemia-reperfusion injury models used in the preclinical cardioprotection studies and the inappropriate design and execution of the clinical cardioprotection studies. This important issue was the main topic of discussion of the UCL-Hatter Cardiovascular Institute 6th International Cardioprotection Workshop, the outcome of which has been published in this article as the "Hatter Workshop Recommendations". These have been proposed to provide guidance on the design and execution of both preclinical and clinical cardioprotection studies in order to facilitate the translation of future novel cardioprotective strategies for patient benefit.

\section{Kitakaze}

Cardiovascular Division of Medicine, National Cardiovascular Centre, Suita, Osaka, Japan

S. Lecour

Hatter Institute for Cardiology Research,

University of Cape Town, Cape Town, South Africa

R. Mentzer

School of Medicine, Wayne State University, Detroit, MI, USA

M. Ovize

Hôpital L. Pradel, Hospices Civils de Lyon, 59, Blvd. Pinel, 69394 Lyon Cedex 03, France

\section{R. Shannon}

Department of Medicine, Penn Medicine,

University of Pennsylvania, Philadelphia, PA, USA

G. Walkinshaw

FibroGen, Inc., 409 Illinois Street,

San Francisco, CA 94158, USA 
Keywords Cardioprotection - Preconditioning . Postconditioning · Animal models · Translation

\section{Introduction}

Ischemic heart disease (IHD) is the leading cause of death worldwide. As such, novel therapeutic strategies for protecting the heart against ischemia-reperfusion injury (IRI) are urgently needed to: reduce myocardial injury, preserve cardiac function, prevent the development of heart failure, and improve clinical outcomes in patients with IHD $[42,66]$. However, a major obstacle to this process has been the inability to successfully translate novel cardioprotective strategies discovered in the research laboratory setting directly into the clinical arena [38].

This important issue was the main topic of discussion of the 6th Hatter Institute International Workshop on Cardioprotection, which was held this year in Mauritius, an Island in which diabetes and associated IHD are major contributors to overall morbidity and mortality. It was organized together with the Working Group of Cellular Biology of the Heart of the European Society of Cardiology. The main agenda of this International Workshop was to discuss and formulate a set of recommendations for the design and execution of future studies on cardioprotection in both the research laboratory and the clinical setting, in order to facilitate the translation of future novel cardioprotective strategies for patient benefit. One crucial aspect of this endeavour was to recognise the limitations in the design and execution of current experimental laboratory and clinical cardioprotection studies, a feature which was also highlighted by the NHLI Working Group in 2004 [7].

\section{Inadequacy of the animal models of IRI}

It is well accepted that the majority of animal models of IRI currently used to investigate novel cardioprotective strategies are inadequate representations of the clinical setting [7, 33, $36,56]$, given the size and age of the animals used as well as their lack of co-morbidities and co-treatments. Ideally, one would have to prove efficacy of a certain cardioprotective intervention in animal experiments by the reduction in myocardial infarct (MI) size and/or improvement of prognosis under all mimicked clinical circumstances; however, this is unrealistic and it was agreed that the following recommendations should be proposed.

Animal selection

1. Species The response of the heart to IRI and cardioprotective strategies will vary depending on the species used. Often small animal MI models have been used to investigate cardioprotection, since knockout and/or silencing of target proteins is possible in these models. However, more expensive, large animal (canine, porcine, primate) MI models are needed to confirm results of small animal experiments before clinical testing, since the temporal and spatial development of MI as well as certain signalling pathways in small animals differ from that in larger mammals and humans [21, 53, 55]. Therefore, small animal MI models may be used for preliminary 'screening' of a novel cardioprotective strategy, as long as the latter is also demonstrated to be efficacious in at least one large animal MI model.

2. Age Patients with IHD usually present between the ages of 55 and 65 years, whereas many experimental studies use young adult rats and mice (aged 3-4 months) which are equivalent to the human age of 7-10 years [6]. Several studies have reported that with age the myocardium can become resistant to various cardioprotective strategies including ischemic preconditioning [48] and postconditioning [5, 44]. Therefore, it is essential to demonstrate that any novel cardioprotective strategy is effective in suitably aged animal hearts. The easiest and most convenient species for such experiments are mice and rats in which the human age of 55-65 years corresponds to about 21-24 months of age [6].

3. Sex Both male and female patients suffer from IHD, yet most preclinical cardioprotective studies are restricted to using male animals only. Several studies suggest that gender can impact on the myocardial sensitivity to different cardioprotective strategies [15, 56]. Therefore, it is necessary to establish whether or not a novel cardioprotective strategy is effective in both male and female animals.

4. Co-morbidities Patients with IHD are likely to have a number of co-morbid conditions at the time of presentation, many of which can influence the sensitivity of the myocardium to certain cardioprotective strategies [15]. Preclinical studies suggest that in the presence of diabetes $[45,50,62]$ or the metabolic syndrome [63], the threshold for cardioprotection may be elevated or cardioprotection may be even absent (reviewed in [15]). Therefore, it is essential to establish whether or not a novel cardioprotective strategy is effective in the presence in one or more of these comorbidities.

5. Medical therapy Many patients with pre-existing IHD take several types of medical therapy which may influence the effects of any novel cardioprotective strategy. Certain sulphonylureas such as glibenclamide may block the cardioprotection elicited by ischemic 
conditioning [39]. On the other hand, nicorandil, ACEinhibitors, nitrates, statin therapy may inadvertently precondition the myocardium. Furthermore, on admission with an MI, additional therapy such as oxygen, morphine and nitrates may all precondition the myocardium or at least lower the threshold for protection. Similarly, patients undergoing elective coronary artery bypass graft (CABG) surgery are likely to receive inhalational anaesthetics such as isoflurane which has been reported to precondition the heart [58]. It is difficult to reproduce all concomitant therapy in preclinical animal models of cardioprotection but it is crucial to be aware of the limitations of such models without medication especially when co-morbidities are present. In designing the preclinical experiment to take all these factors into consideration, it may not be feasible or necessary to allow for every different combination and permutation. It may well be that prioritizing the confounders and medical therapy is more useful. In this respect, we would recommend that it is more important to address age before gender and the other co-morbidities. In terms of concomitant medical therapy, we would recommend the investigation of at least one relevant medical therapy.

The animal model of IRI

1. The type of model Acute coronary occlusion in animal models of MI is most often achieved by external occlusion of a healthy coronary artery. In contrast, in most patients presenting with an acute MI, the acute coronary occlusion is due to the formation of a thrombus at the site of a ruptured unstable atherosclerotic plaque. Furthermore, the process of reperfusion by percutaneous coronary intervention (PCI) in the clinical setting is more likely to be associated with a residual stenosis and with thrombotic embolisation than in the animal model [24]. Thus, the nature of the coronary artery occlusion and the methods used to re-establish perfusion in addition to the proinflammatory state of an acute MI may influence the effect of the cardioprotective strategy. Finding an animal model to reproduce these effects is a daunting task.

The clinical setting which most closely resembles the most frequently used animal model of MI is the IHD patient presenting acutely with a complete thrombotic coronary artery occlusion (a ST-elevation myocardial infarction, STEMI) undergoing myocardial reperfusion using PCI. Whether this animal MI model should be used to investigate novel cardioprotective strategies destined for use in different clinical settings such as cardiac arrest, cardiac transplantation, PCI or CABG surgery may be questioned. However, other more appropriate animal models are available to simulate the myocardial injury sustained in these clinical settings (see Table 1).

2. Duration of ischemia The index ischemic time used in animal MI models is usually fixed having been selected to create a moderate to large infarct when expressed as the area at risk (AAR), but still allowing for protection to occur [42]. Furthermore, due to the fixed ischemic time the variation of the extent of MI is relatively small making any demonstration of cardioprotection easier. In contrast, MI patients present with widely varying ischemic times at the hospital (in the range of $1-12 \mathrm{~h}$ ) and display huge variability in MI size even allowing for the same ischemic time because of the large number of confounding factors which can influence infarct size. Therefore, the demonstration of any kind of cardioprotection is complicated, requiring quite often subgroup analyses of patient data, thereby increasing the sample size.

Table 1 Matching the animal IRI model for investigating the novel cardioprotective strategy to the clinical setting in which it is intended for use

\begin{tabular}{|c|c|c|}
\hline Clinical setting & Animal IRI model & $\begin{array}{l}\text { Example animal } \\
\text { studies }\end{array}$ \\
\hline $\begin{array}{l}\text { STEMI patient undergoing PCI } \\
\text { (regional acute myocardial ischemia and reperfusion) }\end{array}$ & $\begin{array}{l}\text { Animal model of MI } \\
\text { (regional acute myocardial ischemia and reperfusion) }\end{array}$ & $\begin{array}{l}\text { Mice, rats, } \\
\text { rabbits, dogs } \\
\text { and pigs [56] }\end{array}$ \\
\hline $\begin{array}{l}\text { Stable IHD patient undergoing CABG surgery (global myocardial } \\
\text { ischemia and reperfusion with cardioplegia, coronary } \\
\text { microembolization and manual handling) }\end{array}$ & $\begin{array}{l}\text { Use of cardio-pulmonary bypass for circulatory support } \\
\text { (global myocardial ischemia and } \\
\text { reperfusion } \pm \text { cardioplegia) }\end{array}$ & $\begin{array}{l}\text { Dogs, pigs and } \\
\text { sheep }[30,31]\end{array}$ \\
\hline $\begin{array}{l}\text { Cardiac arrest patient in which circulation has been restored } \\
\text { (global myocardial ischemia and reperfusion) }\end{array}$ & $\begin{array}{l}\text { Animal model of cardiac arrest and reperfusion } \\
\text { (global myocardial ischemia and reperfusion) }\end{array}$ & $\begin{array}{l}\text { Rats [59] and } \\
\text { pigs [40] }\end{array}$ \\
\hline $\begin{array}{l}\text { Cardiac transplant patient (global myocardial ischemia and } \\
\text { reperfusion with cardioplegia) }\end{array}$ & $\begin{array}{l}\text { Heterotopic heart transplantation with global } \\
\text { myocardial ischemia and reperfusion } \pm \text { cardioplegia }\end{array}$ & Pigs [34] \\
\hline $\begin{array}{l}\text { Patient undergoing PCI (limited myocardial ischemic injury and } \\
\text { coronary microembolization) }\end{array}$ & Coronary microembolization & Pigs [52] \\
\hline
\end{tabular}


3. Duration of reperfusion The reperfusion time used in animal MI models is usually fixed and ranges from 0.5 to $3 \mathrm{~h}$ depending on the particular model used. In rat and rabbit in vivo models the ultimate MI size by tetrazolium staining has been reported to be established after $3 \mathrm{~h}$ of reperfusion [67]. However, studies suggest that MI size in the canine heart continues to increase even after $6 \mathrm{~h}$ of reperfusion [68], although this issue is controversial [16]. For MI patients, the duration of reperfusion obviously depends on the time when one measures MI size. Therefore, the acute infarct-limiting effects of a novel cardioprotective strategy should be assessed when infarct size is fully developed but before remodelling occurs.

4. Endpoint of cardioprotection In most animal experiments, the reduction of MI size is taken as the endpoint of cardioprotection. MI size depends on the area at risk and on residual blood flow, and therefore MI size as a fraction of area at risk is the more robust endpoint of protection. The relation of MI size as a fraction of AAR to residual blood flow is probably the best endpoint of cardioprotection in animal experiments [53]. Recovery of contractile function is not only a function of MI size, but also of stunning and therefore less suited as an endpoint of protection. Of note, in clinical studies MI size is estimated from biomarkers and imaging and considered only a surrogate for clinical outcome.

It is clear from the previously published preclinical literature that an abundance of novel cardioprotective strategies have been discovered. However, the investigation of a particular novel cardioprotective strategy using a systematic, step-wise, collaborative approach has been lacking. Therefore, the formation of a collaborative network of research laboratories to test a single novel cardioprotective strategy in a range of animal MI models may be required to determine whether consistent cardioprotection is observed across species and laboratories. This would have the potential advantage of increasing the probability of a successful translation into the clinical setting, or alternatively, discouraging the initiation of a clinical trial that is destined to be unsuccessful. In 2002, this approach was used to investigate the cardioprotective effect of an adenosine A1 agonist. In this study, a multicentre randomised controlled double-blind experimental animal study was performed in three different laboratories [4].

\section{Clinical settings of IRI}

The pathophysiology of IRI obviously varies with the clinical setting. The purest example of classical IRI is the
IHD patient presenting acutely with a complete thrombotic coronary artery occlusion (a STEMI) who undergoes PCI reperfusion therapy. Although IRI may contribute to the myocardial injury sustained in a number of other clinical settings such as CABG surgery, cardiac arrest and transplantation, other factors such as manual handling of the heart and coronary embolization [23] may come into play. They need to be taken into consideration when analysing the results. It should be noted, however, that the problem of distal embolization may also occur with PCI and the contribution of IRI per se to this form of injury is probably minor. Clearly, the appropriate animal IRI model should be selected to test the novel cardioprotective strategy to match the intended clinical setting in which it is to be applied to (see Table 1).

\section{Designing clinical cardioprotective studies of STEMI patients undergoing PCI}

The patient

1. Site of the infarct A recent analysis has suggested that only $25 \%$ of all STEMI patients will have infarcts large enough to realize benefit from any adjunctive therapy applied at the time of PCI [38]. Thus, the PCI patients who are most likely to benefit immediately from a cardioprotective strategy in the short term are those patients in whom the therapy is applied as an adjunct to reperfusion therapy and in those which have the larger areas at risk. In general these are patients who present with proximal LAD coronary artery territory infarcts. In contrast, patients presenting with the smaller areas at risk, such as those in the right coronary artery (RCA) and circumflex (Cx) coronary artery territories do not appear to accrue as much benefit from cardioprotective reperfusion therapy [8, 43]. Selecting patients with the smaller infarcts may therefore actually dilute any positive effect elicited by the novel cardioprotective strategy. As such, clinical studies should focus on selecting patients presenting with a proximal LAD infarct only [42]. The disadvantage of this approach is that it may impact negatively on recruitment rates as this population only makes up $30 \%$ of all presenting STEMI patients. It is therefore clear that the AAR should be measured when assessing any novel cardioprotective strategy in the clinical setting.

2. TIMI flow prior to PCI For cardioprotective strategies applied at the time of PCI, it is essential that the intervention is administered prior to myocardial reperfusion. Therefore, patients in which the infarctrelated coronary artery has spontaneously recanalized 
and TIMI coronary blood flow is TIMI $>1$, have already undergone myocardial reperfusion and are unlikely to benefit from the novel cardioprotective strategy and should be excluded. However, this may not be so straightforward, given that some patients can have intermittent reperfusion prior to the catheter laboratory, but have TIMI 0/1 flow prior to PCI. Recent studies suggest that the patients most likely to benefit from a novel cardioprotective strategy applied at the time of PCI are those presenting with TIMI 0/1 flow in the culprit coronary artery [8].

3. Coronary collaterals The presence of coronary collateralisation to the area at risk will reduce MI size in STEMI patients undergoing PCI, thereby confounding any potential beneficial effect with the novel cardioprotective strategy. Patients with visible coronary collaterals (Rentrop grade $\geq 1$ ) [46] on coronary angiography should be excluded from the study. Therefore, it is essential to ensure that the image acquisitions taken during coronary angiography are long enough to visualise coronary collaterals.

4. Duration of chest pain It has been established that STEMI patients accrue mortality benefit from myocardial reperfusion strategies such as thrombolysis and PCI providing they present within $12 \mathrm{~h}$ of the onset of chest pain [17]. Therefore, cardioprotection studies have tended to focus on those patients presenting within $12 \mathrm{~h}$ of chest pain onset. The relationship between the extent of lethal myocardial reperfusion injury and the duration of index ischemia has not been fully elucidated. Whether patients with short ischemic times ( $<3 \mathrm{~h}$ chest pain to PCI time) or patients with prolonged ischemic times (6-12 h chest pain to PCI time) accrue more benefit from an adjunctive reperfusion treatment strategy is unclear. Indeed whether patients who present more than $12 \mathrm{~h}$ following the onset of chest pain, benefit from adjunctive therapy to PCI is unknown.

5. Measurement of the area at risk The assessment of the efficacy of a novel cardioprotective strategy in PCI patients requires the measurement of both the $\mathrm{MI}$ size and the area at risk (AAR). This allows a comparison between STEMI patients with different AAR. Historically, the AAR has been measured in clinical studies using coronary angiography jeopardy scores but the traditional gold-standard technique has been to use nuclear myocardial scanning [8]. The AAR is delineated as the areas of absent radioisotope tracer on a nuclear myocardial scan performed within $6 \mathrm{~h}$ of the injection. Quantification of the AAR by nuclear myocardial scanning can take into account coronary collateralisation because the radioisotope is able to distribute through the collaterals and reduce the AAR, and hence myocardial salvage can be determined correctly even in the presence of coronary collaterals. However, this technique is time-consuming, impractical when offered on a $24-\mathrm{h}$ daily basis, lacks resolution and involves significant radiation to the patient.

An alternative approach to measure the AAR is to assess the hypokinetic segments of the left ventricle using venticulography at the time of PCI [57, 60], although this technique may overestimate the AAR by including areas of myocardial stunning. Cardiac MRI (CMR) may be a promising imaging technique for measuring the AAR. Animal studies have reported that enhanced signal intensity on retrospective T2-weighted CMR from increased myocardial oedema [10] correlates with the AAR in reperfused myocardial infarcts [1, 27]. Preliminary clinical studies suggest that the enhanced T2 signal intensity on CMR scans performed in the first week following PCI correlates with the AAR as measured by the BARI coronary angiography jeopardy score [65] and nuclear myocardial scans [11]. In addition, myocardial salvage as measured by CMR has been linked to clinical outcomes in PCI-treated STEMI patients [14]. The concern with CMR is whether the novel cardioprotective strategy itself may influence the extent of myocardial oedema by reducing it, thereby resulting in an underestimate of the AAR. In this case, CMR may be ineffective as a technique for measuring AAR post PCI. Whichever technique is used to measure the AAR it is essential to use the AAR as a co-variate for analysing MI size reduction, given that patients presenting with the larger areas at risk are those most likely to benefit from the novel cardioprotective strategy.

\section{The intervention}

1. Timing of the cardioprotective strategy The timing of the cardioprotective strategy is critical in the design of clinical studies. The refusal to take heed of preclinical data has been the root cause for some major failures in the clinical field of cardioprotection. Some strategies like sodium-hydrogen exchange inhibitors or therapeutic cooling target myocardial ischemia, while other strategies such as ischemic and pharmacologic postconditioning and remote ischemic conditioning target myocardial reperfusion injury. A cardioprotective strategy which targets myocardial ischemia may still be effective if administered soon after ischemia has started. Such an intervention could be applied by the paramedics in the ambulance, particularly where long transit times to the PCI centre are anticipated and should be encouraged [8]. The ambulance is also the ideal setting for remote ischemic conditioning but often the transit time is too short to complete the 
treatment protocol [8]. Whatever the case, it is essential that any cardioprotective strategy be applied prior to the opening of the infarct-related coronary artery, given the crucial events which occur in the first few minutes of myocardial reperfusion [production of oxidative stress, calcium overload and mitochondrial permeability transition pore (mPTP) opening] $[42,66]$. Clearly, it is imperative that the application of the novel cardioprotective strategy does not in any way delay the onset of myocardial reperfusion.

2. Delivery of cardioprotective strategy A number of pharmacologic postconditioning agents have been identified (e.g. cyclosporine-A). Any such drug should be capable of being administered as a single intravenous or intracoronary bolus so that therapeutic levels will be achieved in a matter of minutes.

\section{Clinical cardioprotective studies of patients undergoing CABG surgery}

The patient

Despite excellent cardioprotection using cold blood cardioplegia, significant peri-operative myocardial injury still occurs in patients undergoing $\mathrm{CABG}$ surgery \pm valve surgery. The cause of this myocardial injury is multi-factorial being attributed to global ischemia-reperfusion injury, coronary embolization and prolonged aortic crossclamp time. The extent of peri-operative myocardial injury can be assessed by measuring serum cardiac enzymes such as CK-MB, troponin-T and troponin-I, the elevation of which has been associated with worse clinical outcomes post-surgery $[9,13,29]$. Surgeons are therefore continually seeking ways to minimise IRI, particularly as more highrisk patients are being operated upon and it is becoming increasingly clear that even mild to moderate elevations in CK-MB and troponin are associated with increased intermediate and long-term mortality.

Similar to the setting of a STEMI in which patients with a larger MI are most likely to benefit from a cardioprotective intervention, the same may apply to patients undergoing $\mathrm{CABG}$ surgery. Therefore, the patients most likely to benefit from a cardioprotective strategy during CABG surgery are those who are most at risk of sustaining significant peri-operative myocardial injury. This group includes patients undergoing 3-vessel CABG surgery with or without valve surgery, redo CABG surgery patients, patients with significant LVH or LV systolic dysfunction, patients with an additive Euroscore of $\geq 6$ and diabetic patients. We believe that it is this group of higher-risk patients who should be selected for studies of novel cardioprotective strategies as they are more likely to experience a greater degree of myocardial IRI from the prolonged cross-clamp and cardio-pulmonary bypass times.

The intervention

A variety of cardioprotective strategies have been tried in the CABG surgery setting in the past. Although the majority of these were unsuccessful, one of the most potentially promising treatment strategies was cariporide, but unfortunately it had off-target cerebral side effects [37]. In the setting of CABG surgery, the novel cardioprotective strategy can be applied either prior to myocardial ischemia (cross-clamping of the aorta), during myocardial ischemia in the cardioplegia solution or at the time of myocardial reperfusion (unclamping the aorta). As noted previously, the preclinical testing of the novel cardioprotective strategy in an animal IRI model which closely resembles the CABG setting should have been previously utilised to verify efficacy (see Table 1).

Which novel cardioprotective strategy should be pursued in the clinical setting?

There are a number of novel cardioprotective strategies which have shown promise in initial proof-of-concept clinical studies. The question is which of these should be taken forward into phase $2 / 3$ clinical studies. Following discussion in the Workshop, it was agreed that the two most promising novel cardioprotective strategies were remote ischemic conditioning (RIC) and cyclosporine-A (CsA).

For RIC, in which cycles of brief ischemia and reperfusion applied to the upper or lower limb protect the myocardium from lethal IRI, there exist extensive preclinical data in a range of animal models including in vivo murine, rat, rabbit and porcine models of MI (reviewed in $[20,56])$. RIC is a non-invasive virtually cost-free cardioprotective strategy which has been shown to be effective when applied both prior to or during the index myocardial ischemia [47] as well as at the onset of myocardial reperfusion [2], lending itself to the clinical settings of CABG surgery [18], planned PCI [25], and STEMI patients receiving PCI [8], settings in which initial proof-of-concept studies have already been successfully performed.

CsA has the advantage of targeting an end-effector of IRI, as opposed to the ever-expanding list of cardioprotective agents which tend to target G-protein coupled receptors and intracellular kinases and other mediators, which may be down-regulated or ineffective in the presence of co-morbidities. Because the main site of action of CsA is probably the mPTP, a purported mitochondrial channel which mediates cardiomyocyte death at the onset 
of myocardial reperfusion, most of the preclinical data in support of its role as a cardioprotective agent have been as an adjunct to myocardial reperfusion [19, 22]. Similarly, there exist extensive preclinical data in a range of animal models including in vitro and in vivo models of MI, as well as in a rabbit model of post-cardiac arrest [12]. However, the in vivo porcine MI model has produced mixed results with CsA for an unclear reason [28, 35, 54]. CsA has also been demonstrated to be effective in human atrial tissue models of simulated IRI [49]. Again, a preliminary proofof-concept clinical study has demonstrated that a single intravenous bolus of CsA given prior to PCI can limit MI size in STEMI patients [43].

Other potentially novel cardioprotective strategies for which there exist both preclinical data and initial proof-ofconcept clinical studies are glucagon-like peptide 1 [41], PKC- $\delta$ inhibition [3], atrial natriuretic peptide [32], and ischemic postconditioning [60].

Clearly, for all these novel cardioprotective strategies preclinical studies are required to determine whether cardioprotection is maintained in the presence of certain confounding factors such as age, sex, diabetes, the metabolic syndrome, hyperlipidemia, hypertension and so forth. In this regard, a recent preclinical study suggests that CsAmediated cardioprotection at the time of myocardial reperfusion was ineffective in Zucker obese rats [26]. This intriguing finding requires confirmation and the mechanism underlying this observation needs further investigation.

In summary, for both CsA and RIC large multi-centred randomised controlled clinical trials are required to confirm their cardioprotective benefit in the clinical setting and investigate whether these interventions impact on clinical outcomes for patient benefit.

\section{Summary}

In order to overcome the obstacles to translation of novel cardioprotective strategies discovered in laboratories into the clinical setting for patient benefit, a set of recommendations may facilitate this process. These are outlined below and include preclinical cardioprotection studies and clinical cardioprotection studies in PCI patients. Clearly, similar recommendations may be introduced for other clinical settings of IRI such as CABG surgery, sudden cardiac arrest, cardiac transplantation, as more evidence becomes available from ongoing studies.

Recommendations for investigating novel cardioprotective strategies in preclinical studies

1. In vitro models A novel cardioprotective strategy should be first investigated using established small animal (murine, rat, rabbit) in vitro models of IRI, including human myocardial tissue models of simulated IRI [51, 64]. The actual animal IRI model used should closely resemble the clinical setting in which it intended to test the novel cardioprotective strategy (see Table 1).

2. In vivo models The novel cardioprotective strategy should then be examined first in small (murine, rat, rabbit) and then in large animal (pig, dog, primate) in vivo studies of IRI. Again, the actual animal IRI model used should closely resemble the clinical setting in which it is intended to test the novel cardioprotective strategy (see Table 1). For animal MI models, reperfusion must be of sufficient duration such that MI size has fully developed; on the other hand, infarct size must be determined before remodelling occurs.

3. Confounders Ideally, the cardioprotective strategy should be demonstrated to still be effective in the presence of one or more confounders and/or medical therapies.

Recommendations for investigating novel cardioprotective strategies in PCI studies

1. Proximal LAD infarcts STEMI patients presenting with a proximal LAD coronary artery infarct are preferred as these patients are those most likely to benefit from the novel cardioprotective strategy.

2. TIMI 0 or 1 prior to PCI Only STEMI patients presenting with TIMI 0/1 coronary flow on coronary angiography prior to PCI should be included in studies investigating novel cardioprotective strategies.

3. No collaterals on coronary angiography Only STEMI patients with no visible coronary collaterals on coronary angiography should be included in studies investigating novel cardioprotective strategies. The exception to this is if the AAR is being measured using nuclear myocardial scanning which takes into account coronary collateralisation.

4. Chest pain $<12 h$ Only STEMI patients presenting within $12 \mathrm{~h}$ of the onset of chest pain should be included in studies investigating novel cardioprotective strategies.

5. Cardioprotective strategy applied prior to reperfusion The intervention must be applied prior to the opening of the culprit coronary artery.

6. Measurement of the area at risk When assessing the efficacy of a novel cardioprotective strategy it is imperative to measure the area at risk.

7. Assessment of the cardioprotective strategy In proofof-concept clinical studies it may be sufficient to measure serum cardiac enzymes (CK-MB and 
troponin-T or I). However, more robust surrogate clinical endpoints include LV ejection fraction (measured by echocardiography, myocardial nuclear scanning or cardiac MRI) and MI size (measured by myocardial nuclear scanning or cardiac MRI). Ultimately, clinical outcome measures such as cardiovascular mortality and hospitalization for heart failure must be determined.

Recommendations for investigating novel cardioprotective strategies in CABG studies

1. Patient selection The investigation of a novel cardioprotective strategy should focus on those patients more likely to sustain significant peri-operative myocardial injury during surgery. These include patients with left ventricular hypertrophy (LVH) or impaired left ventricular (LV) systolic function and patients undergoing 3 -vessel $\mathrm{CABG} \pm$ valve surgery or redo $\mathrm{CABG}$ surgery and diabetic patients.

2. Anaesthetic choice The investigation of the novel cardioprotective strategy should not influence the choice of anaesthetic regimen, even if it comprises inhaled anaesthetic agents such as isoflurane, which have been reported in both preclinical and clinical studies to confer cardioprotection during CABG surgery [58]. It is important that any novel cardioprotective strategy is shown to be effective in the presence of routine medical therapy.

3. Assessment of the cardioprotective strategy In proofof-concept clinical studies, peri-operative release of cardiac enzymes such as CK-MB, troponin-T or I can be used to assess the efficacy of the novel cardioprotective strategy $[18,61]$. Other clinical endpoints include: inotrope score, length of ITU and hospital stay, LV ejection fraction, acute kidney injury, cognitive function, cardiovascular mortality, and hospitalization for heart failure.

Acknowledgments We would like to thank the Working Group of Cellular Biology of the Heart of the European Society of Cardiology for their kind support of this Workshop.

Open Access This article is distributed under the terms of the Creative Commons Attribution Noncommercial License which permits any noncommercial use, distribution, and reproduction in any medium, provided the original author(s) and source are credited.

\section{References}

1. Aletras AH, Tilak GS, Natanzon A, Hsu LY, Gonzalez FM, Hoyt RF Jr, Arai AE (2006) Retrospective determination of the area at risk for reperfused acute myocardial infarction with T2-weighted cardiac magnetic resonance imaging: histopathological and displacement encoding with stimulated echoes (DENSE) functional validations. Circulation 113:1865-1870

2. Andreka G, Vertesaljai M, Szantho G, Font G, Piroth Z, Fontos G, Juhasz ED, Szekely L, Szelid Z, Turner MS, Ashrafian H, Frenneaux MP, Andreka P (2007) Remote ischaemic postconditioning protects the heart during acute myocardial infarction in pigs. Heart 93:749-752

3. Bates E, Bode C, Costa M, Gibson CM, Granger C, Green C, Grimes K, Harrington R, Huber K, Kleiman N, Mochly-Rosen D, Roe M, Sadowski Z, Solomon S, Widimsky P (2008) Intracoronary KAI-9803 as an adjunct to primary percutaneous coronary intervention for acute ST-segment elevation myocardial infarction. Circulation 117:886-896

4. Baxter GF, Hale SL, Miki T, Kloner RA, Cohen MV, Downey JM, Yellon DM (2000) Adenosine A1 agonist at reperfusion trial (AART): results of a three-center, blinded, randomized, controlled experimental infarct study. Cardiovasc Drugs Ther 14:607-614

5. Boengler K, Buechert A, Heinen Y, Roeskes C, Hilfiker-Kleiner D, Heusch G, Schulz R (2008) Cardioprotection by ischemic postconditioning is lost in aged and STAT3-deficient mice. Circ Res 102:131-135

6. Boengler K, Schulz R, Heusch G (2009) Loss of cardioprotection with ageing. Cardiovasc Res 83:247-261

7. Bolli R, Becker L, Gross G, Mentzer R Jr, Balshaw D, Lathrop DA (2004) Myocardial protection at a crossroads: the need for translation into clinical therapy. Circ Res 95:125-134

8. Botker HE, Kharbanda R, Schmidt MR, Bottcher M, Kaltoft AK, Terkelsen CJ, Munk K, Andersen NH, Hansen TM, Trautner S, Lassen JF, Christiansen EH, Krusell LR, Kristensen SD, Thuesen L, Nielsen SS, Rehling M, Sorensen HT, Redington AN, Nielsen TT (2010) Remote ischaemic conditioning before hospital admission, as a complement to angioplasty, and effect on myocardial salvage in patients with acute myocardial infarction: a randomised trial. Lancet 375:727-734

9. Brener SJ, Lytle BW, Schneider JP, Ellis SG, Topol EJ (2002) Association between CK-MB elevation after percutaneous or surgical revascularization and three-year mortality. J Am Coll Cardiol 40:1961-1967

10. Breuckmann F, Nassenstein K, Bucher C, Konietzka I, Kaiser G, Konorza T, Naber C, Skyschally A, Gres P, Heusch G, Erbel R, Barkhausen J (2009) Systematic analysis of functional and structural changes after coronary microembolization: a cardiac magnetic resonance imaging study. JACC Cardiovasc Imaging 2:121-130

11. Carlsson M, Ubachs JF, Hedstrom E, Heiberg E, Jovinge S, Arheden H (2009) Myocardium at risk after acute infarction in humans on cardiac magnetic resonance: quantitative assessment during follow-up and validation with single-photon emission computed tomography. JACC Cardiovasc Imaging 2:569-576

12. Cour M, Loufouat J, Paillard M, Augeul L, Goudable J, Ovize M, Argaud L (2010) Inhibition of mitochondrial permeability transition to prevent the post-cardiac arrest syndrome: a pre-clinical study. Eur Heart J Apr 28 [Epub ahead of print]

13. Croal BL, Hillis GS, Gibson PH, Fazal MT, El Shafei H, Gibson G, Jeffrey RR, Buchan KG, West D, Cuthbertson BH (2006) Relationship between postoperative cardiac troponin I levels and outcome of cardiac surgery. Circulation 114:1468-1475

14. Eitel I, Desch S, Fuernau G, Hildebrand L, Gutberlet M, Schuler G, Thiele H (2010) Prognostic significance and determinants of myocardial salvage assessed by cardiovascular magnetic resonance in acute reperfused myocardial infarction. J Am Coll Cardiol 55:2470-2479 
15. Ferdinandy P, Schulz R, Baxter GF (2007) Interaction of cardiovascular risk factors with myocardial ischemia/reperfusion injury, preconditioning, and postconditioning. Pharmacol Rev 59:418-458

16. Ferrera R, Benhabbouche S, Bopassa JC, Li B, Ovize M (2009) One hour reperfusion is enough to assess function and infarct size with TTC staining in Langendorff rat model. Cardiovasc Drugs Ther 23:327-331

17. Fibrinolytic Therapy Trialists' (FTT) Collaborative Group (1994) Indications for fibrinolytic therapy in suspected acute myocardial infarction: collaborative overview of early mortality and major morbidity results from all randomised trials of more than 1000 patients. Fibrinolytic Therapy Trialists' (FTT) Collaborative Group. Lancet 343:311-322

18. Hausenloy DJ, Mwamure PK, Venugopal V, Harris J, Barnard M, Grundy E, Ashley E, Vichare S, Di Salvo C, Kolvekar S, Hayward M, Keogh B, MacAllister RJ, Yellon DM (2007) Effect of remote ischaemic preconditioning on myocardial injury in patients undergoing coronary artery bypass graft surgery: a randomised controlled trial. Lancet 370:575-579

19. Hausenloy DJ, Yellon DM (2003) The mitochondrial permeability transition pore: its fundamental role in mediating cell death during ischaemia and reperfusion. J Mol Cell Cardiol 35:339-341

20. Hausenloy DJ, Yellon DM (2008) Remote ischaemic preconditioning: underlying mechanisms and clinical application. Cardiovasc Res 79:377-386

21. Heusch G, Boengler K, Schulz R (2008) Cardioprotection: nitric oxide, protein kinases, and mitochondria. Circulation 118:19151919

22. Heusch G, Boengler K, Schulz R (2010) Inhibition of mitochondrial permeability transition pore opening: the Holy Grail of cardioprotection. Basic Res Cardiol 105:151-154

23. Heusch G, Kleinbongard P, Bose D, Levkau B, Haude M, Schulz R, Erbel R (2009) Coronary microembolization: from bedside to bench and back to bedside. Circulation 120:1822-1836

24. Heusch G, Schulz R (2009) Neglect of the coronary circulation: some critical remarks on problems in the translation of cardioprotection. Cardiovasc Res 84:11-14

25. Hoole SP, Heck PM, Sharples L, Khan SN, Duehmke R, Densem CG, Clarke SC, Shapiro LM, Schofield PM, O'Sullivan M, Dutka DP (2009) Cardiac Remote Ischemic Preconditioning in Coronary Stenting (CRISP Stent) Study: a prospective, randomized control trial. Circulation 119:820-827

26. Huhn R, Heinen A, Hollmann MW, Schlack W, Preckel B, Weber NC (2009) Cyclosporine A administered during reperfusion fails to restore cardioprotection in prediabetic Zucker obese rats in vivo. Nutr Metab Cardiovasc Dis Oct 8. [Epub ahead of print]

27. Ibanez B, Prat-Gonzalez S, Speidl WS, Vilahur G, Pinero A, Cimmino G, Garcia MJ, Fuster V, Sanz J, Badimon JJ (2007) Early metoprolol administration before coronary reperfusion results in increased myocardial salvage: analysis of ischemic myocardium at risk using cardiac magnetic resonance. Circulation 115:2909-2916

28. Karlsson LO, Zhou AX, Larsson E, Astrom-Olsson K, Mansson C, Akyurek LM, Grip L (2010) Cyclosporine does not reduce myocardial infarct size in a porcine ischemia-reperfusion model. J Cardiovasc Pharmacol Ther 15:182-189

29. Kathiresan S, Servoss SJ, Newell JB, Trani D, MacGillivray TE, Lewandrowski K, Lee-Lewandrowski E, Januzzi JL Jr (2004) Cardiac troponin $\mathrm{T}$ elevation after coronary artery bypass grafting is associated with increased one-year mortality. Am J Cardiol 94:879-881

30. Kerendi F, Kirshbom PM, Halkos ME, Wang NP, Kin H, Jiang R, Zhao ZQ, Kanter KR, Guyton RA, Vinten-Johansen J (2006)
Thoracic Surgery Directors Association Award. Cobalt chloride pretreatment attenuates myocardial apoptosis after hypothermic circulatory arrest. Ann Thorac Surg 81:2055-2062

31. Kharbanda RK, Li J, Konstantinov I, Cheung M, White P, Frndova H, Stokoe J, Cox P, Vogel M, Van Arsdell G, MacAllister $\mathrm{R}$, Redington A (2006) Remote ischaemic preconditioning protects against cardiopulmonary bypass induced tissue injury-a preclinical study. Heart 92:1506-1511

32. Kitakaze M, Asakura M, Kim J, Shintani Y, Asanuma H, Hamasaki T, Seguchi O, Myoishi M, Minamino T, Ohara T, Nagai Y, Nanto S, Watanabe K, Fukuzawa S, Hirayama A, Nakamura N, Kimura K, Fujii K, Ishihara M, Saito Y, Tomoike H, Kitamura S (2007) Human atrial natriuretic peptide and nicorandil as adjuncts to reperfusion treatment for acute myocardial infarction (J-WIND): two randomised trials. Lancet 370:1483-1493

33. Kloner RA, Rezkalla SH (2004) Cardiac protection during acute myocardial infarction: where do we stand in 2004? J Am Coll Cardiol 44:276-286

34. Konstantinov IE, Li J, Cheung MM, Shimizu M, Stokoe J, Kharbanda RK, Redington AN (2005) Remote ischemic preconditioning of the recipient reduces myocardial ischemiareperfusion injury of the denervated donor heart via a KATP channel-dependent mechanism. Transplantation 79:1691-1695

35. Lie RH, Stoettrup N, Sloth E, Hasenkam JM, Kroyer R, Nielsen TT (2010) Post-conditioning with cyclosporine A fails to reduce the infarct size in an in vivo porcine model. Acta Anaesthesiol Scand 54:804-813

36. Ludman AJ, Yellon DM, Hausenloy DJ (2010) Cardiac preconditioning for ischaemia: lost in translation. Dis Model Mech 3:35-38

37. Mentzer RM Jr, Bartels C, Bolli R, Boyce S, Buckberg GD, Chaitman B, Haverich A, Knight J, Menasche P, Myers ML, Nicolau J, Simoons M, Thulin L, Weisel RD (2008) Sodiumhydrogen exchange inhibition by cariporide to reduce the risk of ischemic cardiac events in patients undergoing coronary artery bypass grafting: results of the EXPEDITION study. Ann Thorac Surg 85:1261-1270

38. Miura T, Miki T (2008) Limitation of myocardial infarct size in the clinical setting: current status and challenges in translating animal experiments into clinical therapy. Basic Res Cardiol 103:501-513

39. Mocanu MM, Maddock HL, Baxter GF, Lawrence CL, Standen NB, Yellon DM (2001) Glimepiride, a novel sulfonylurea, does not abolish myocardial protection afforded by either ischemic preconditioning or diazoxide. Circulation 103:3111-3116

40. Niemann JT, Youngquist S, Rosborough JP, Shah AP, Phan QT, Filler SG (2010) Infliximab attenuates early myocardial dysfunction after resuscitation in a swine cardiac arrest model. Crit Care Med 38:1162-1167

41. Nikolaidis LA, Mankad S, Sokos GG, Miske G, Shah A, Elahi D, Shannon RP (2004) Effects of glucagon-like peptide-1 in patients with acute myocardial infarction and left ventricular dysfunction after successful reperfusion. Circulation 109:962-965

42. Ovize M, Baxter GF, Di Lisa F, Ferdinandy P, Garcia-Dorado D, Hausenloy DJ, Heusch G, Vinten-Johansen J, Yellon DM, Schulz $\mathrm{R}$ (2010) Postconditioning and protection from reperfusion injury: where do we stand? Position paper from the Working Group of Cellular Biology of the Heart of the European Society of Cardiology. Cardiovasc Res 87:406-423

43. Piot C, Croisille P, Staat P, Thibault H, Rioufol G, Mewton N, Elbelghiti R, Cung TT, Bonnefoy E, Angoulvant D, Macia C, Raczka F, Sportouch C, Gahide G, Finet G, Andre-Fouet X, Revel D, Kirkorian G, Monassier JP, Derumeaux G, Ovize M (2008) Effect of cyclosporine on reperfusion injury in acute myocardial infarction. N Engl J Med 359:473-481

44. Przyklenk K, Maynard M, Darling CE, Whittaker P (2008) Aging mouse hearts are refractory to infarct size reduction with postconditioning. J Am Coll Cardiol 51:1393-1398 
45. Przyklenk K, Maynard M, Greiner DL, Whittaker P (2010) Cardioprotection with postconditioning: loss of efficacy in murine models of type- 2 and type- 1 diabetes. Antioxid Redox Signal Jun 27 [Epub ahead of print]

46. Rentrop KP, Cohen M, Blanke H, Phillips RA (1985) Changes in collateral channel filling immediately after controlled coronary artery occlusion by an angioplasty balloon in human subjects. J Am Coll Cardiol 5:587-592

47. Schmidt MR, Smerup M, Konstantinov IE, Shimizu M, Li J, Cheung M, White PA, Kristiansen SB, Sorensen K, Dzavik V, Redington AN, Kharbanda RK (2007) Intermittent peripheral tissue ischemia during coronary ischemia reduces myocardial infarction through a KATP-dependent mechanism: first demonstration of remote ischemic perconditioning. Am J Physiol Heart Circ Physiol 292:H1883-H1890

48. Schulman D, Latchman DS, Yellon DM (2001) Effect of aging on the ability of preconditioning to protect rat hearts from ischemiareperfusion injury. Am J Physiol Heart Circ Physiol 281:H1630 H1636

49. Shanmuganathan S, Hausenloy DJ, Duchen MR, Yellon DM (2005) Mitochondrial permeability transition pore as a target for cardioprotection in the human heart. Am J Physiol Heart Circ Physiol 289:H237-H242

50. Sivaraman V, Hausenloy DJ, Wynne AM, Yellon DM (2009) Preconditioning the diabetic human myocardium. J Cell Mol Med 14:1740-1746

51. Sivaraman V, Mudalgiri NR, Di Salvo C, Kolvekar S, Hayward M, Yap J, Keogh B, Hausenloy DJ, Yellon DM (2007) Postconditioning protects human atrial muscle through the activation of the RISK pathway. Basic Res Cardiol 102:453-459

52. Skyschally A, Gres P, Hoffmann S, Haude M, Erbel R, Schulz R, Heusch G (2007) Bidirectional role of tumor necrosis factoralpha in coronary microembolization: progressive contractile dysfunction versus delayed protection against infarction. Circ Res 100:140-146

53. Skyschally A, Schulz R, Heusch G (2008) Pathophysiology of myocardial infarction: protection by ischemic pre- and postconditioning. Herz 33:88-100

54. Skyschally A, Schulz R, Heusch G (2010) Cyclosporine A at reperfusion reduces infarct size in pigs. Cardiovasc Drugs Ther 24:85-87

55. Skyschally A, van Caster P, Boengler K, Gres P, Musiolik J, Schilawa D, Schulz R, Heusch G (2009) Ischemic postconditioning in pigs: no causal role for RISK activation. Circ Res 104:15-18

56. Skyschally A, van Caster P, Iliodromitis EK, Schulz R, Kremastinos DT, Heusch G (2009) Ischemic postconditioning: experimental models and protocol algorithms. Basic Res Cardiol 104:469-483

57. Staat P, Rioufol G, Piot C, Cottin Y, Cung TT, L'Huillier I, Aupetit JF, Bonnefoy E, Finet G, Andre-Fouet X, Ovize M (2005) Postconditioning the human heart. Circulation 112:2143-2148

58. Symons JA, Myles PS (2006) Myocardial protection with volatile anaesthetic agents during coronary artery bypass surgery: a metaanalysis. Br J Anaesth 97:127-136

59. Tang W, Weil MH, Sun S, Pernat A, Mason E (2000) K(ATP) channel activation reduces the severity of postresuscitation myocardial dysfunction. Am J Physiol Heart Circ Physiol 279:H1609-H1615

60. Thibault H, Piot C, Staat P, Bontemps L, Sportouch C, Rioufol G, Cung TT, Bonnefoy E, Angoulvant D, Aupetit JF, Finet G, Andre-Fouet X, Macia JC, Raczka F, Rossi R, Itti R, Kirkorian G, Derumeaux G, Ovize M (2008) Long-term benefit of postconditioning. Circulation 117:1037-1044

61. Thielmann M, Kottenberg E, Boengler K, Raffelsieper C, Neuhaeuser M, Peters J, Jakob H, Heusch G (2010) Remote ischemic preconditioning reduces myocardial injury after coronary artery bypass surgery with crystalloid cardioplegic arrest. Basic Res Cardiol 105:657-664

62. Tsang A, Hausenloy DJ, Mocanu MM, Carr RD, Yellon DM (2005) Preconditioning the diabetic heart: the importance of akt phosphorylation. Diabetes 54:2360-2364

63. Wagner C, Kloeting I, Strasser RH, Weinbrenner C (2008) Cardioprotection by postconditioning is lost in WOKW rats with metabolic syndrome: role of glycogen synthase kinase 3 beta. J Cardiovasc Pharmacol 52:430-437

64. Walker DM, Walker JM, Pugsley WB, Pattison CW, Yellon DM (1995) Preconditioning in isolated superfused human muscle. J Mol Cell Cardiol 27:1349-1357

65. Wright J, Adriaenssens T, Dymarkowski S, Desmet W, Bogaert J (2009) Quantification of myocardial area at risk with T2-weighted CMR: comparison with contrast-enhanced CMR and coronary angiography. JACC Cardiovasc Imaging 2:825-831

66. Yellon DM, Hausenloy DJ (2007) Myocardial reperfusion injury. N Engl J Med 357:1121-1135

67. Ytrehus K, Liu Y, Tsuchida A, Miura T, Liu GS, Yang XM, Herbert D, Cohen MV, Downey JM (1994) Rat and rabbit heart infarction: effects of anesthesia, perfusate, risk zone, and method of infarct sizing. Am J Physiol 267:H2383-H2390

68. Zhao ZQ, Nakamura M, Wang NP, Velez DA, Hewan-Lowe KO, Guyton RA, Vinten-Johansen J (2000) Dynamic progression of contractile and endothelial dysfunction and infarct extension in the late phase of reperfusion. J Surg Res 94:133-144 